\title{
Analisis Aktifitas Otot dengan Elektroda Ag/AgCL Menggunakan Labview 2015
}

\author{
Dewi Lestari ${ }^{1}$, Elvan Yuniarti ${ }^{2}$ \\ ${ }^{1}$ Program Studi Sistem Informasi,Fakultas Industri Kreatif dan Telematika Universitas Trilogi Jakarta \\ ${ }^{2}$ Program Studi Fisika, Fakultas Sains dan Teknologi, Universitas Syarif Hidayatullah Jakrta
}

\section{KEYWORDS}

Electromyography, $\mathrm{Ag} / \mathrm{AgCl}$ Electrode, $\mathrm{AT}$ mega328 Microcontroller, LabVIEW 2015

\section{CORRESPONDENCE}

Phone: 085697355048

E-mail: dewy24@trilogi.ac.id

\section{PENDAHULUAN}

Elektromiografi merupakan alat yang di gunakan untuk merekan aktivitas elektrik yang ada pada otot dengan pengukuran saat kontrasi atau dalam keadaan relax. Perekaman aktivitas otot menggunakan elektroda yang ditempelkan pada permukaan secara langsung pada kulit. Pada umumnya elektroda yang dipakai adalah jarum atau elektroda yang ditusuk kedalam otot. Elektroda tersebut akan merekam tegangan yang dihasilkan dari pergerakan otot, saat kontraksi maupun relaksasi serat otot dan hasilnya sangat kecil range dalam millivolt. Oleh karena itu dibutuhkan penguat untuk pembacaan sinyal yang lebih baik.

Penelitian tentang EMG memanfaatkan sinyal elektrik yang ada dalam tubuh manusia agar dapat digunakan sebagaiinput kendali suatu sistem yang dalam hal ini mengambil sinyal-sinyal EMG hasil dari aktivitas otot yang mengandung informasi tentang keadaan otot tersebutPenelitian ini menggunakan elektroda $\mathrm{Ag} / \mathrm{AgCl}$ sebagai pembaca beda potensial pada otot saat kontraksi dan relaksasi. Elektroda $\mathrm{Ag} / \mathrm{AgCl}$ merupakan elektroda yang terdiri dari logam perak yang dilapisi dengan perak klorida, larutan KCI, dan membran (Robinson, 2005)..

Elektroda $\mathrm{Ag} / \mathrm{AgCl}$ ini adalah elektroda pembanding dengan parameter pengukuran dapat berupa arus listrik, beda potensial listrik, muatan listrik, impedansi maupun kapasitan (Rouessac,
2007). Elektroda pada umumnya ada dua jenis, yaitu elektroda permukaan (surface electrode) dan elektroda jarum atau kabel (wire or needle electrode). Pada eksperiment kali ini menggunakan surface elektroda $\mathrm{Ag} / \mathrm{AgCl}$ (perak kloria) yang menghasilkan sinyal EMG.

\section{METODE}

Methods Penelitian tentang aktivitas otot ini dilakukan di laboratorium terpadu UIN Syarif hidayatullah Jakarta

\section{Rancang bangun alat perekam elektrik otot EMG.}

Pada penelitian menggunakan bahan dan alat yaitu elektroda $\mathrm{Ag} / \mathrm{AgCl}$, wire, mikrokontroler AT Mega328, serta rangkaian block diagram pada software LabVIEW untuk menampilkan gambar sinyal hasil perekaman elektroda. Gambar adalah flowchar pengukuran sinyal EMG saat kontraksi maupun relaksasi. 


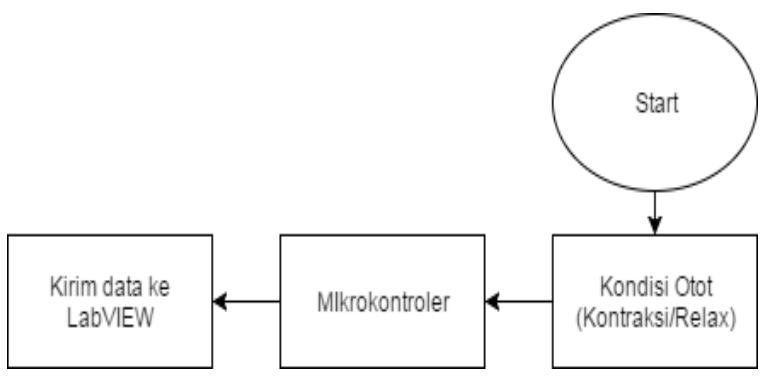

Gambar 1. Flowchart pengukuran sinyal EMG

\section{Pemasangan sensor elektroda pada lengan}

Penelitian ini menggunakan elektroda ekg untuk mengukur kontraksi maupun relaksasi pada otot. Elektroda yang digunakan dalam pengukuran ada tiga yang letaknya

1. Elektroda pertama diletakan dilengan bagian atas

2. Elektroda kedua diletakan di lengan bagian bawah

3. Elektroda yang ketiga dipasang dibagian bawa siku Gambar dibawah ini menunjukan letak pemasangan elektroda dan program labview yang digunakan untuk pengukuran otot alat EMG.

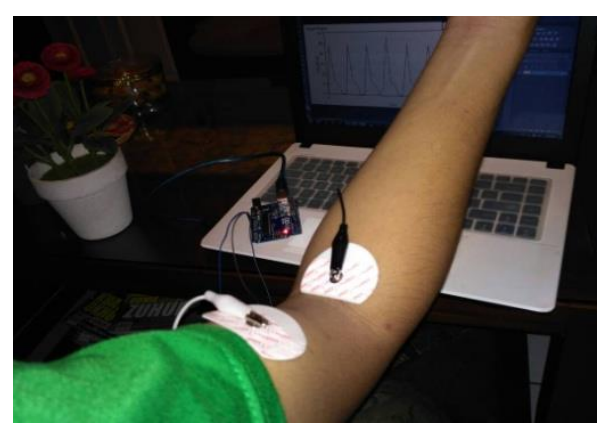

Gambar 2. Design sederhana alat deteksi sinyal EMG pada otot lengan

\section{Pengambilan data sinyal}

Pengambilan sinyal EMG dilakukan sebanyak lima data. Dengan variasi kontraksi dan relax. gambar menunjukan pemasangan elektroda saat kontraksi dan relaksasi:

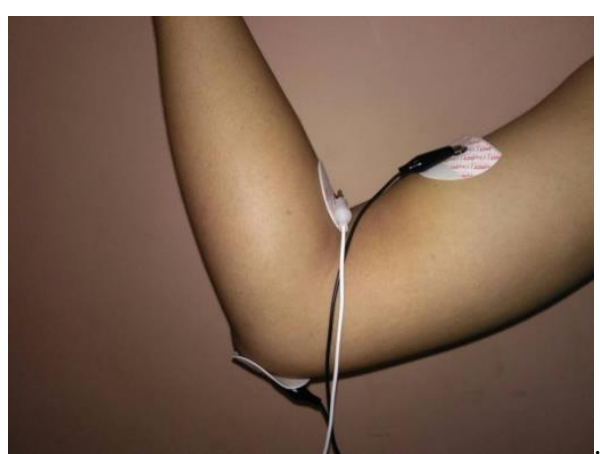

Gambar 3. Pemasangan elektroda saat kondisi kontraksi

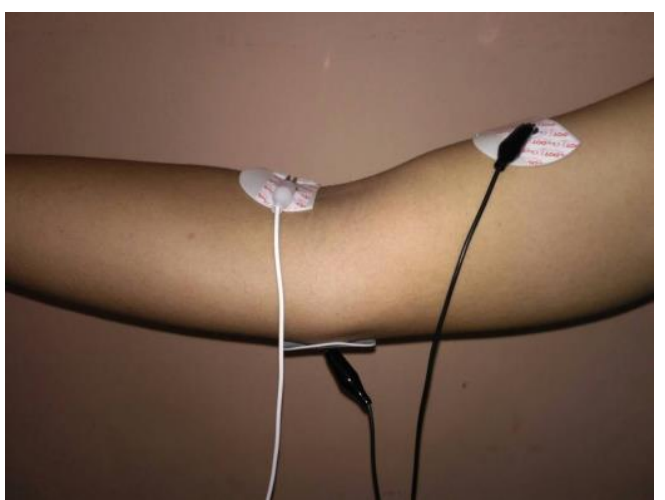

Gambar 4. Pemasangan elektroda saat kondisi relax

\section{Rangkaian mikrokontroler AT Mega328 alat EMG.}

Rangkaian mikrokontroler ini berfungsi sebagai penerima output hasil dari sensor elektroda $\mathrm{Ag} / \mathrm{AgCl}$ yang mendeteksi sinyal yang dihasilkan dari pergerakan otot saat kontraksi atau saat kondisi relax. Konfigurasi PIN pada mikrokontroler ini memiliki sistem minimum.

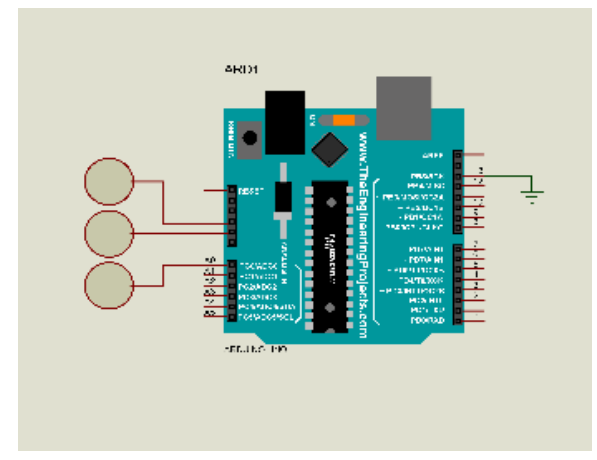

Gambar 5. Skema proteus dan elektroda Diagram block pada LabVIEW.

Program labview digunakan sebagai tampilan data yang dihasilkan dari elektroda. Diagram blok labview ini terdiri dari data pengiriman serial yang menggunakan program visa pada software labview.

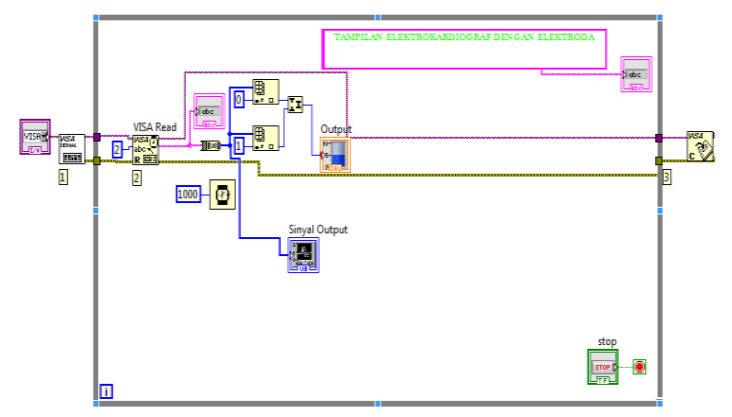

Gambar 6. Blok Diagram Pengolahan Sinyal EMG dengan Labview 2015 


\section{HASIL DAN PEMBAHASAN}

Dari percobaan yang telah dilakukan diperoleh data percobaan sebagai berikut

Table 1. Hasil Tegangan saat relaksasi dan kontraksi

\begin{tabular}{lll}
\hline Keadaan Otot & & \\
\hline No & Relaksasi $(\boldsymbol{m} \boldsymbol{V})$ & Relaksasi $(\boldsymbol{m} \boldsymbol{V})$ \\
\hline 1 & 58.09 & 64.74 \\
2 & 59.08 & 58.09 \\
3 & 58.12 & 63.94 \\
4 & 61.43 & 67.18 \\
5 & 61.35 & 72.15 \\
\hline
\end{tabular}

Dan dari data tersebut dibuat grafik hubungan antara keadaan otot (relaksasi/kontraksi) dengan tegangan keluaran (output) sebagai berikut:

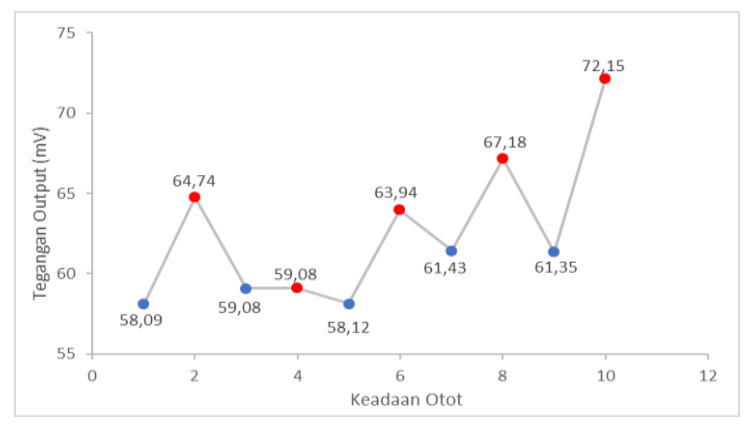

Gambar 7. Grafik hubungan antara keadaan otot relaksasi dan kontraksi

Dari data percobaan dan grafik yang telah dibuat terlihat bahwa nilai tegangan keluran (output) lebih besar ketika saat otot dalam keadaan kontraksi daripada pada saat otot dalam keadaan relaksasi. Pada keadaan relaksasi tegangan keluran memiliki nilai rata-rata sebesar $59,614 \mathrm{mV}$ sedangkan pada keadaan kontraksi tegangan keluaran memiliki nilai rata-rata sebesar $65,418 \mathrm{mV}$.

\section{Analisis data menggunakan program Labview.}

Analisis ini bertujuan untuk mengetahui karakteristik dari pergerakan otot saat relax dan saat kontraksi dengan melihat sinyal atau gelombang yang dihasilkan. Pada eksperimen yang dilakukan pengambilan data lima kali dengan variasi yang random/acak. Dengan carmelihat nilai dari amplitudo untuk kontraksi dan relaksasi. Berikut ini hasil sinyal EMG dengan tampilan data gelombang dari Lab VIEW:

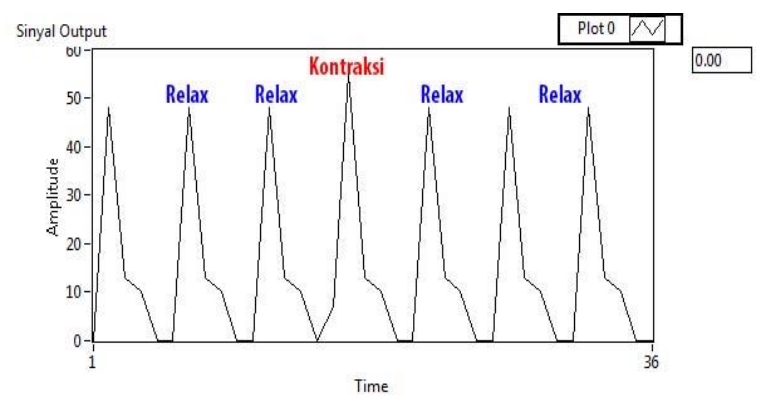

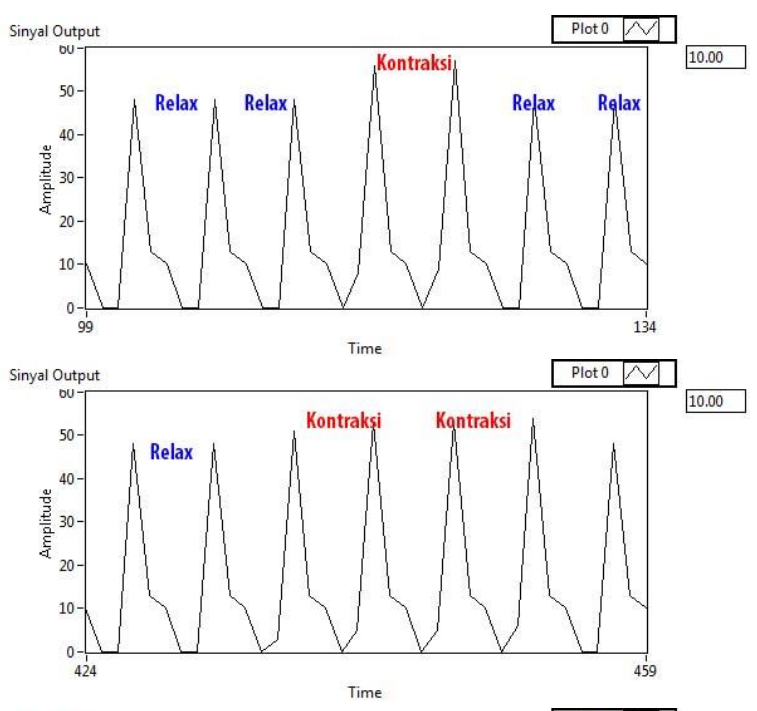

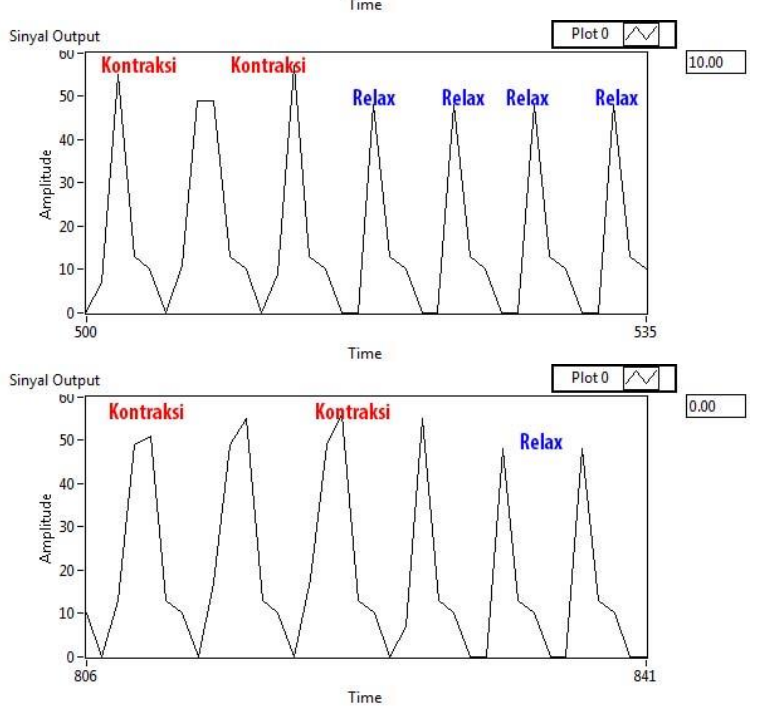

Gambar 8. Sinyal EMG dengan Variable Amplitudo dan Time.

Dari lima data tersebut karakteristik dari sinyal yang dihasilkan adalah saat kontraksi menghasilkan amplitudo yang maksimal tinggi sekitar 57, sedangkan kondisi saat relax, amplitudo yang dihasilkan lebih rendah yaitu rata-rata 50 .

\section{KESIMPULAN}

Dari hasil penelitian dihasilkan simpulan untuk menentukan karakteristik otot kontraksi dan otot saat relax bahwa aktivitas listrik ini terjadi diseluruh bagian tubuh baik itu di otak, otot dan di jantung. Frekuensi dari setiap kegiatan yang dialakukan pasti akan berbeda, hal ini dapat diketahui dengan elektroda yang dipasang pada kulit. Tegangan keluaran yang dihasilkan pada otot biseps pada saat ototdalam keadaan relaksasi akan lebih kecil daripada saat otot dalam keadaan kontraksi. Hal ini dikarenakan sistem otot itu sendiri yang menghambat atau mengurangi aliran listrik yang mengalir pada otot. Besarnya amplitude antara kontraksi dan relax sangat berbeda tipis. Amplitude maksimal 57 saat kontraksi dan rata-rata amplitudo 50 untuk kondisi relax. Gelombang yang dihasilkan labview masih sangat belum ideal, dikarenakan banyaknya noise dan bentuk sinyal yang masih lemah. Artinya masih diperlukan rangkaian penguat tambahan untuk menghasilkan sinyal yang lebih ideal. 


\section{UCAPAN TERIMA KASIH}

Penulis mengucapkan rasa terima kasih yang sebesar-besarnya kepada suami tercinta Asep Nurdiansyah yang selalu memberikan motivasi penulis demi penelitian ini dan Rekan Penelitian Ibu Elvan Yuniarti yang membantu menyelesaikan penelitian dengan baik serta berbagai pihak yang telah membantu yang tidak dapat disebutkan satu persatu.

\section{REFERENSI}

[1] Pratiwi, I. (2015).Letak Elektroda Elektromiografi pada Upper Extremity Muscle.Yogyakarta: publikasi Ilmiah ums.

[2] Anonim. (2016, 01 24). Pengertian dan Fungsi Arduino Mikrokontroller.dan-fungsi-arduino-mikrokontroller

[3] Webster, John. G.2009.Medical Instrumentation.United States of America : John Wiley \& Sons Inc.

[4] Gowda, Akshata. 2013. Control 4 Smart Home System using LabVIEW. International Journal of Engineering Science and Innovative Technology (IJESIT).

[5] Sumathi, Surekha, (2007), LabVIEW base Advanced Instrumentation Systems, Springer, Verlag Berlin Heidelberg.

[6] Setiawan, J.D., (2011), Introduction to LabVIEW, UNDIP, Semarang.

[7] Rachnad Setiawan, 1999, Sistem Pengukuran Sinyal Biomedika, Institut Sepuluh Nopember Surabaya.

[8] Muhammad Rivai, 2000, Sistem Pemrosesan Sinyal, Institut Sepuluh NopemberSurabaya

[9] Azman, A.W., Naeem, J., Mustafah, Y.M., July. "The design o non-invasive functional electrical stimulation (FES) for restoration of muscle function", in: 2012 International Conference on Computer and Communication Engineering (ICCCE). Presented at the 2012 International Conference onComputer and Communication Engineering (ICCCE), pp.612- 616.

[10] Modul Biomedical Signal Amplifier mod EB-B1/EV, Electronica Veneta.

[11] Robert F Coughlin, Frederick F Driscoll, 1992, Penguat Operasional Dan Rangkaian Terpadu Linear, Edisi kedua, diterjemahkan oleh Herman

[12] Widodo Soemitro, Jakarta, Erlangga. Willis J. Tompkins, 1995, Biomedical Digital Signal Processing, University of Wiconsin-Madison, Prentice Hall PTR, Upper Saddle River, New Jersey. 